\title{
Summary of Calculations Performed to Evaluate the Structural Integrity of the 6- Pack Container Pallet
}

C.A. Hrousis

\section{October 1, 1999}

U.S. Department of Energy

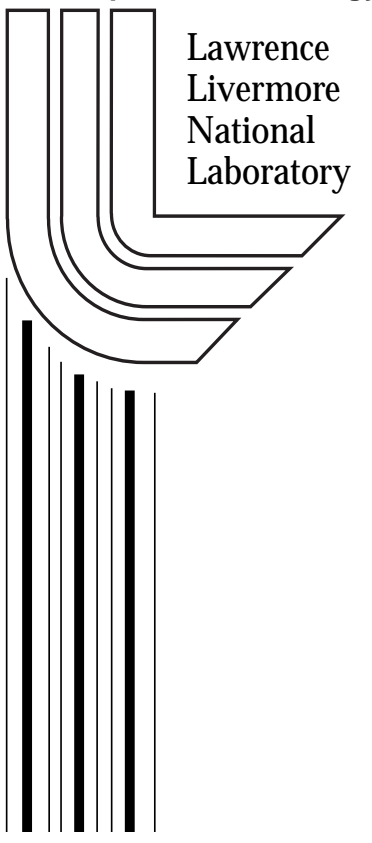




\section{DISCLAIMER}

This document was prepared as an account of work sponsored by an agency of the United States Government. Neither the United States Government nor the University of California nor any of their employees, makes any warranty, express or implied, or assumes any legal liability or responsibility for the accuracy, completeness, or usefulness of any information, apparatus, product, or process disclosed, or represents that its use would not infringe privately owned rights. Reference herein to any specific commercial product, process, or service by trade name, trademark, manufacturer, or otherwise, does not necessarily constitute or imply its endorsement, recommendation, or favoring by the United States Government or the University of California. The views and opinions of authors expressed herein do not necessarily state or reflect those of the United States Government or the University of California, and shall not be used for advertising or product endorsement purposes.

Work performed under the auspices of the U. S. Department of Energy by the University of California Lawrence Livermore National Laboratory under Contract W-7405-Eng-48.

This report has been reproduced directly from the best available copy.

Available to DOE and DOE contractors from the

Office of Scientific and Technical Information

P.O. Box 62, Oak Ridge, TN 37831

Prices available from (423) 576-8401

http://apollo.osti.gov/bridge/

Available to the public from the National Technical Information Service

U.S. Department of Commerce 5285 Port Royal Rd., Springfield, VA 22161 http://www.ntis.gov/

OR Lawrence Livermore National Laboratory Technical Information Department's Digital Library http://www.llnl.gov/tid/Library.html 


\title{
Summary of Calculations Performed to Evaluate the Structural Integrity of the 6-Pack Container Pallet
}

\author{
Constantine A. Hrousis \\ Advanced Engineering Analysis Group \\ Defense Technologies Engineering Division \\ Lawrence Livermore National Laboratory
}

1 October 1999

\begin{abstract}
The 6-Pack Container Pallet is a space-frame structure, designed by Mason \& Hanger Corp. to hold six AL-R8 containers together in a convenient bundle. The AL-R8 containers hold nuclear weapon components that require special care and consideration. The primary purpose of the 6pack assembly is storage, but there is some manipulation as the 6-pack is loaded, moved and stacked.
\end{abstract}

Recently, there has been an upgrade to a new AL-R8-SI container that is heavier than its predecessor was. The analysis discussed herein was conducted to ensure that the increased stresses due to the heavier containers are within design safety limits.

At this time, however, there is disagreement as to what the strength requirements for the 6-pack pallet are. Depending on which classification applies to the structure, a factor of safety (yield stress over design stress) of 3.0 or more may need to be satisfied.

This report documents strength analyses of loaded 6-packs performed at Lawrence Livermore National Laboratory (LLNL). The entire 6-pack assembly was discretized into a mesh with a total of 38682 first-order finite elements. The stresses were found for four characteristic load cases using the implicit code NIKE3D. This was a static strength analysis only. Dynamic loading was not considered. Stability, also, was not addressed.

There are two 6-pack pallet designs under consideration: one that uses 1/2" diameter bolts and one with $3 / 8$ " bolts. In both cases, the maximum torque applied to the bolts is 55 in-lbf. This analysis finds the minimum factor of safety based on yield to be less than 3.0 in the main load path of both the $1 / 2$ " and 3/8" diameter bolt designs. In general, the peak stresses found in the $1 / 2$ " bolt design are less than those of the $3 / 8$ " bolt design.

At the welded ends of the main tube section that spans the length of the pallet, the minimum safety factor is 2.14 when $1 / 2$ " bolts are used and 1.77 when $3 / 8$ " bolts are used. Minimum safety factors of 1.91 and 1.78 were found around the bolt holes in the lateral supports in the 1/2"' bolt and 3/8" bolt designs, respectively. 


\section{Introduction}

The 6-Pack Container Pallet is a structure used to bundle six AL-R8 containers so that they can be moved, stacked and stored conveniently. The cylindrical drum-shaped AL-R8 containers are typically used to store nuclear weapon components. Though the container itself provides adequate protection against contamination, a sudden impact may still render the contents unusable. Therefore, it is important to ensure that the containers are not subject to unnecessary hazardous conditions. At the time of writing, the specific strength requirements for the 6-pack are still in debate.

Usually, the strength criteria for acceptance of a design include meeting or exceeding a mechanical factor of safety. When in doubt, a conservative yet common guideline is a factor of safety of at least 3.0 based on yield (see LLNL Mechanical Engineering Design Safety Standards Manual, Section E.5). This is to say that the yield strength of the material at any particular location in the structure must be at least a factor of 3.0 times the greatest mechanical stress found at that location for any encountered loading condition. The purpose of the safety factor criterion is to provide a cushion against weaknesses in the actual materials and fabrication methods that go into making the structure, not weaknesses or limitations in the analysis that predicts the stresses encountered. Therefore, refinement in analysis and predicting stresses more accurately is not a justification for relaxing safety factor requirements.

A safety factor requirement is usually based on yield strength because material behavior beyond the yield point can be variable and sometimes unreliable. Furthermore, frequent cycling close to or beyond yield can begin to aggravate fatigue mechanisms of failure. Because of these considerations, it is advisable that until less stringent guidelines are approved, a factor of safety of 3.0 based on yield should be satisfied at all locations along the main load path of the structure. Specifically excluded from this requirement are members that are designed to yield to accommodate varying container dimensions. For instance, the cover is expected to exhibit some yielding when barrels of differing heights are inserted and the bolts are torqued down. The cover therefore will be considered exempt from the safety factor of 3.0 requirement for the purposes of this study. The proper authorities, however, should formally approve this exemption.

Mason \& Hanger Corp. originally designed the 6-pack pallet, illustrated in Figure 1, for lighter containers and different bolts. The largest part of the pallet is its base, an assemblage of structural steel plates, angles and tube sections, all welded together. The cover is made of plates and angles, welded also. The six containers are placed onto the base, with the cover above them. Six grade- 5 carriage bolts are threaded up through the base, then through the cover, then torqued down. This is the basic "assembled" configuration of the pallet, later known as load case \#1. Though a drawing of an empty 6-pack is shown in Figure 1, diagrams and pictures of 6-packs with all containers in place and bolted together are shown in Figures 2 through 7.

This study is motivated by concern over increased demands placed on the pallet, particularly from a $78 \%$ increase in the container weight. This increase is due to a transition from the old AL-R8 containers to AL-R8-SI containers with an improved "sealed insert" design. The decision for acceptance of continued use of the current design may depend largely upon whether or not 
this pallet is designated a "lifting fixture". If so, its safety factor on yield would definitely need to be 3.0 or greater. The purpose of this report and the analysis it details is not to accept or reject the current design of the 6-pack pallet for use with sealed insert containers, but to provide an accurate assessment of stress levels during its use. The decision to accept, reject or modify the current design for this use is up to those who establish acceptable risk levels for the handling of ALR8-SI containers and their contents.

The 6-pack pallet is a complex space-frame structure. Load paths through the structure are not intuitive. This can make simple hand calculations either too conservative or unreliable. Because of this complexity, detailed finite element calculations of the entire structure were deemed necessary for the best possible understanding of the structure. This report details assumptions made during the finite element model's development, the methods used to perform its analysis, and the results found and their implications.

\section{Assumptions}

There are several assumptions made during the analysis and limitations to its results that are worth noting. Firstly, this analysis addresses only strength concerns, not stability. The 6-pack pallet with sealed insert containers is reported by Mason \& Hanger to have passed any necessary stability criteria. Secondly, this analysis does not consider any kind of dynamic loading (such as drop, impact, vibration or seismic loading). Severe dynamic loading could potentially increase stresses by a factor of two. However, assuming smooth, slow and gradual loading, static analysis is appropriate.

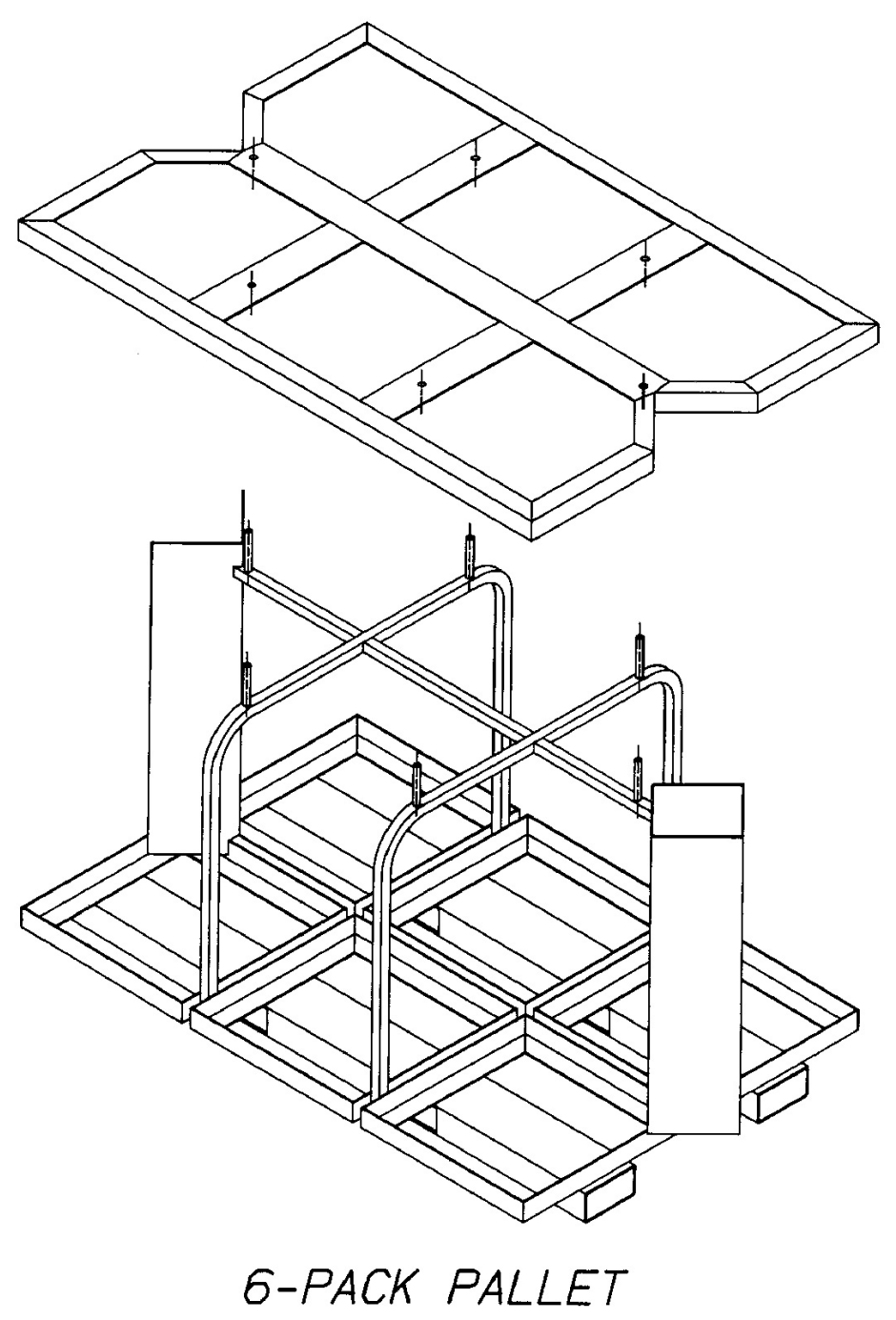

FIGURE 1: A drawing of the 6-pack cover (above) and base (below). Once the six containers are in place, the assembly is held together by the six bolts. Drawing is from Mason \& Hanger Co., Inc. 
Two current 6-pack designs exist: one with 1/2" nominal diameter bolts and one with 3/8" bolts. Mechanical Engineering Design by Shigley and Mischke and many other references contain a design equation relating the tightening torque $(\mathrm{T})$ on a bolt (of nominal diameter $\mathrm{D}$ ) with the axial preload in the bolt $(\mathrm{P})$ by means of a lubricity or nut factor $(\mathrm{K})$. The relationship between these quantities is T $=\mathrm{K} \mathrm{D} \mathrm{P.} \mathrm{Knowing} \mathrm{that} \mathrm{the} \mathrm{bolts} \mathrm{used} \mathrm{in} \mathrm{the} \mathrm{6-pack} \mathrm{assembly} \mathrm{are} \mathrm{zinc-}$ plated, analyses by Mason \& Hanger and this analysis assume $\mathrm{K}$ to be 0.25 , although for most generic applications $\mathrm{K}$ is usually assumed to be about 0.2 . In this situation, use of $\mathrm{K}=0.25$ results in a significantly smaller preload, and is ultimately less conservative. The maximum torque to which the bolts are subjected is reported to be 55 in-lbf. For the two bolt sizes of interest, the corresponding axial bolt preloads are calculated as follows:

For 1/2" bolts: $\quad \mathrm{P}=\mathrm{T} /(\mathrm{K} \mathrm{D})=55 \mathrm{in}-\mathrm{lbf} /(0.25 \times 0.5 \mathrm{in})=440 \mathrm{lbf}$

For 3/8" bolts: $\quad \mathrm{P}=\mathrm{T} /(\mathrm{K} \mathrm{D})=55 \mathrm{in}-\mathrm{lbf} /(0.25 \times 0.375 \mathrm{in})=587 \mathrm{lbf}$

Note that because the amount of torque applied is the same, the $3 / 8$ " bolt design requires more severe bolt preloading. Washers and boltheads, modeled as bonded to their bolts, are assumed to have a diameter twice the nominal diameter of the bolts. It is assumed that forces can only be transmitted from the cover to the base through the six bolts and through the containers themselves; there is no direct contact between the base and the cover.

It is assumed that all AL-R8-SI containers are identical, having a weight of $213.6 \mathrm{lbf}$, a height of 30 in and a diameter of $18.4 \mathrm{in}$. The coefficient of friction $(\mu)$ for steel-on-steel is assumed to be 0.3 . All steel is assumed to have a modulus of elasticity of $2.9 \times 10^{7} \mathrm{psi}$, a Poisson's ratio of 0.29 , and a density of $0.283 \mathrm{lbm} / \mathrm{in}^{3}$. A-36 steel plate and angles are assumed to yield at $36000 \mathrm{psi}$, while the A500-68 tubing has a yield stress of 46000 psi. Once yielded, steel parts are assumed to have a hardening modulus of $1.1 \times 10^{5} \mathrm{psi}$. The grade- 5 carriage bolts are assumed to have a yield strength of 92000 psi.

Four static load cases are considered. In "Assembled" load case \#1 (shown in Figure 2), the 6pack base is placed flat on the floor with containers standing centered in their bays with the cover on top. Gravity is applied first, then the bolts are tightened to their appropriate axial preloads.

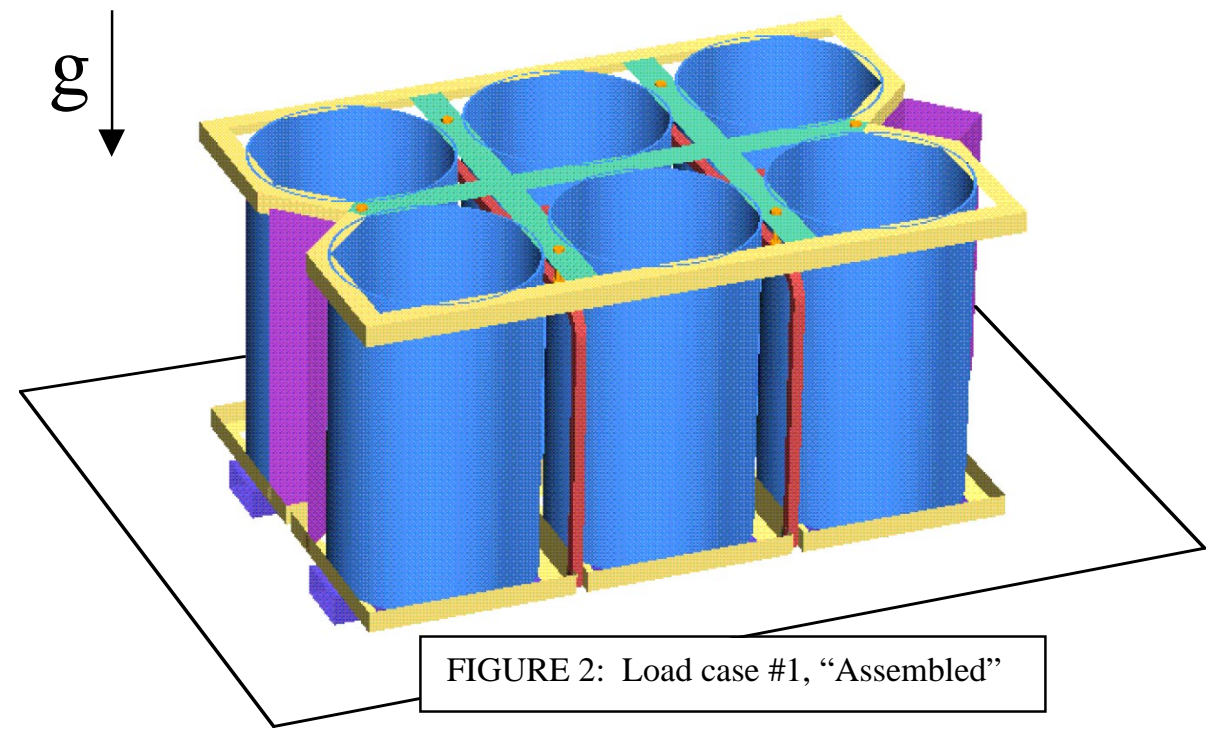




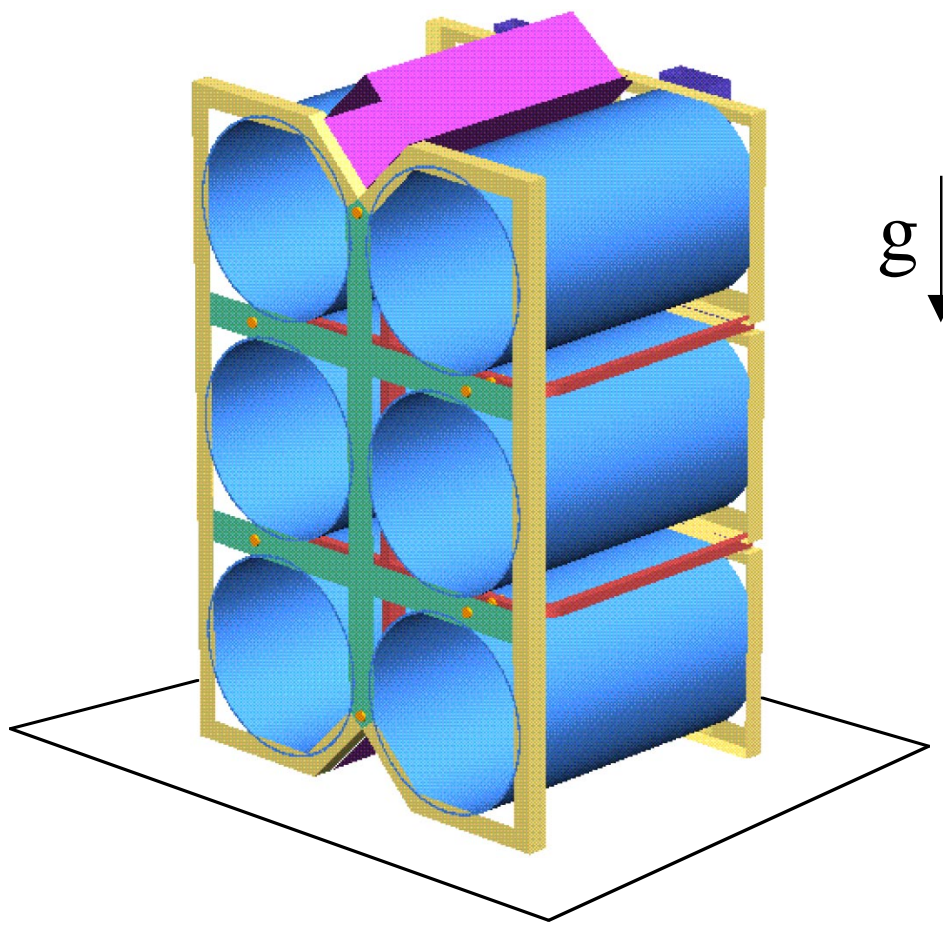

In "Upright" load case \#2 (shown in Figure 3), the assembled 6-pack from load case \#1 is assumed to have been turned $90^{\circ}$ statically (so slowly that dynamic forces can be neglected) so that the gravity vector now points from the full diamond support toward the half diamond support. The 6-pack rests on the floor only on the ends of the forklift tubes and the cover flanges on the half-diamond end of the assembly. The stresses in the bolts change considerably because of this new orientation. For a few parts of the assembly, this tends to be the most severe load case.

FIGURE 3: Load case \#2, "Upright"

In "Stacked" load case \#3 (shown in Figure 4), the upright 6-pack from load case \#2 has the equivalent weight of another identical 6pack assembly applied on the full-diamond end, distributed only on the upward pointing cover flanges and forklift tube ends. The magnitudes and locations of the applied loads are based on a 6-pack's total weight and center of gravity. Precise alignment is assumed between the contacting surfaces of the two 6-packs. Misalignment would probably cause some stress concentrations without altering the main load path significantly.

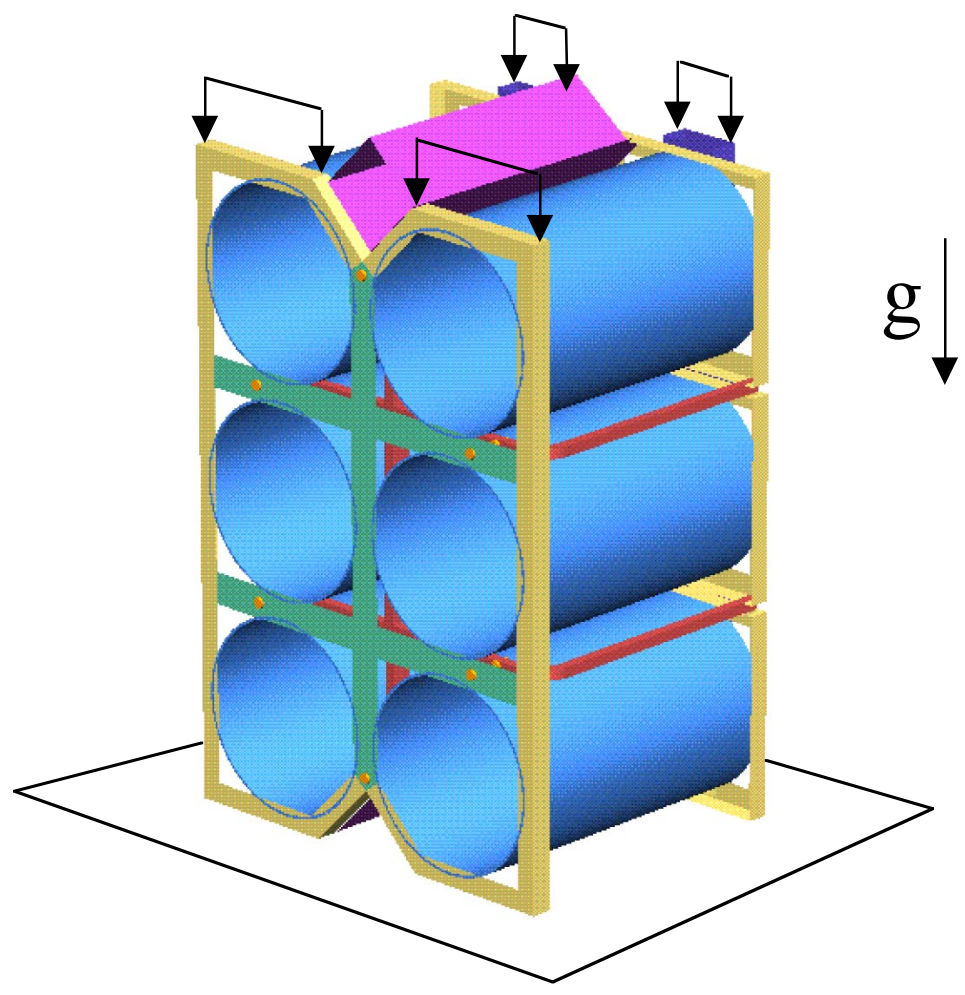

FIGURE 4: Load case \#3, "Stacked" 

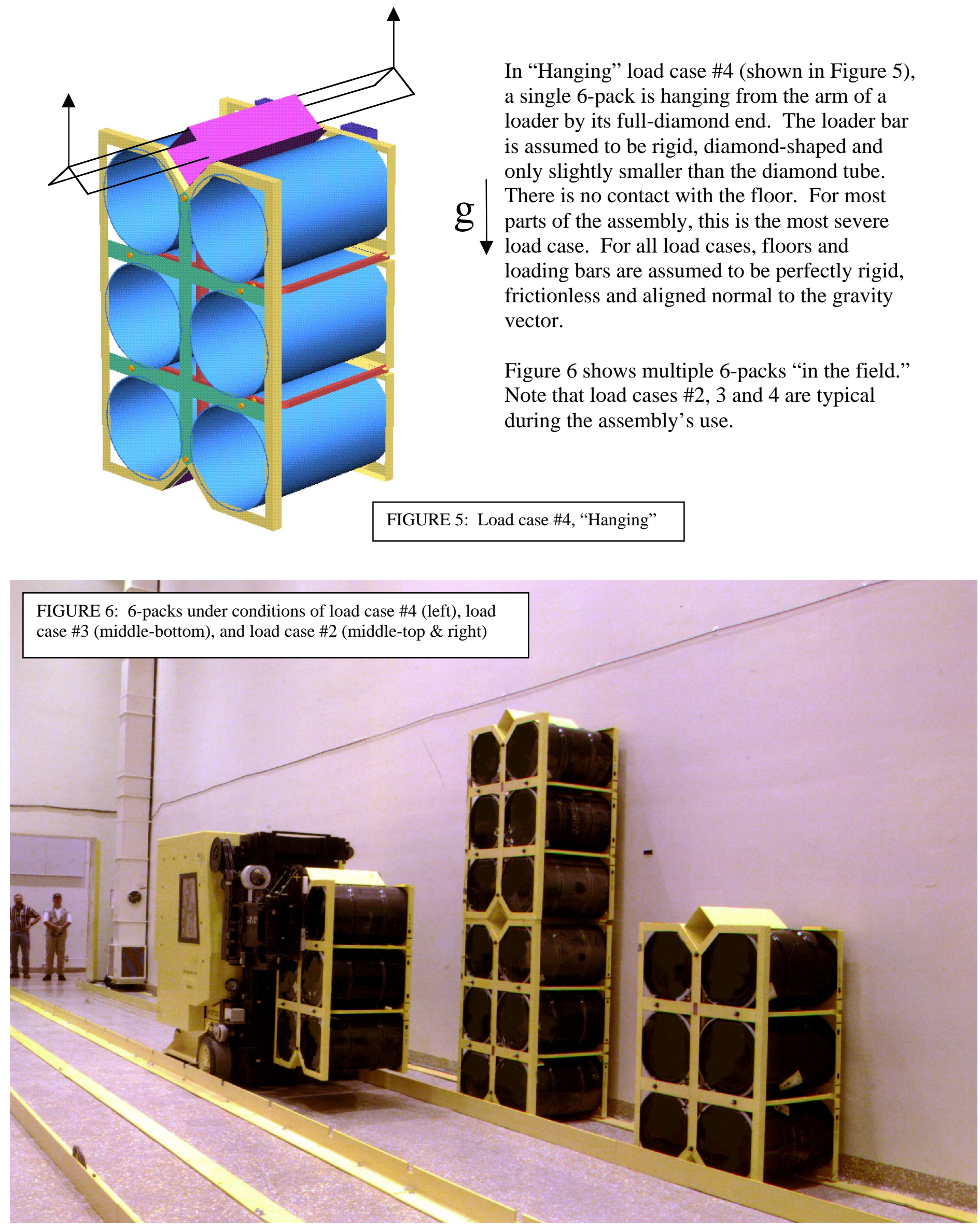


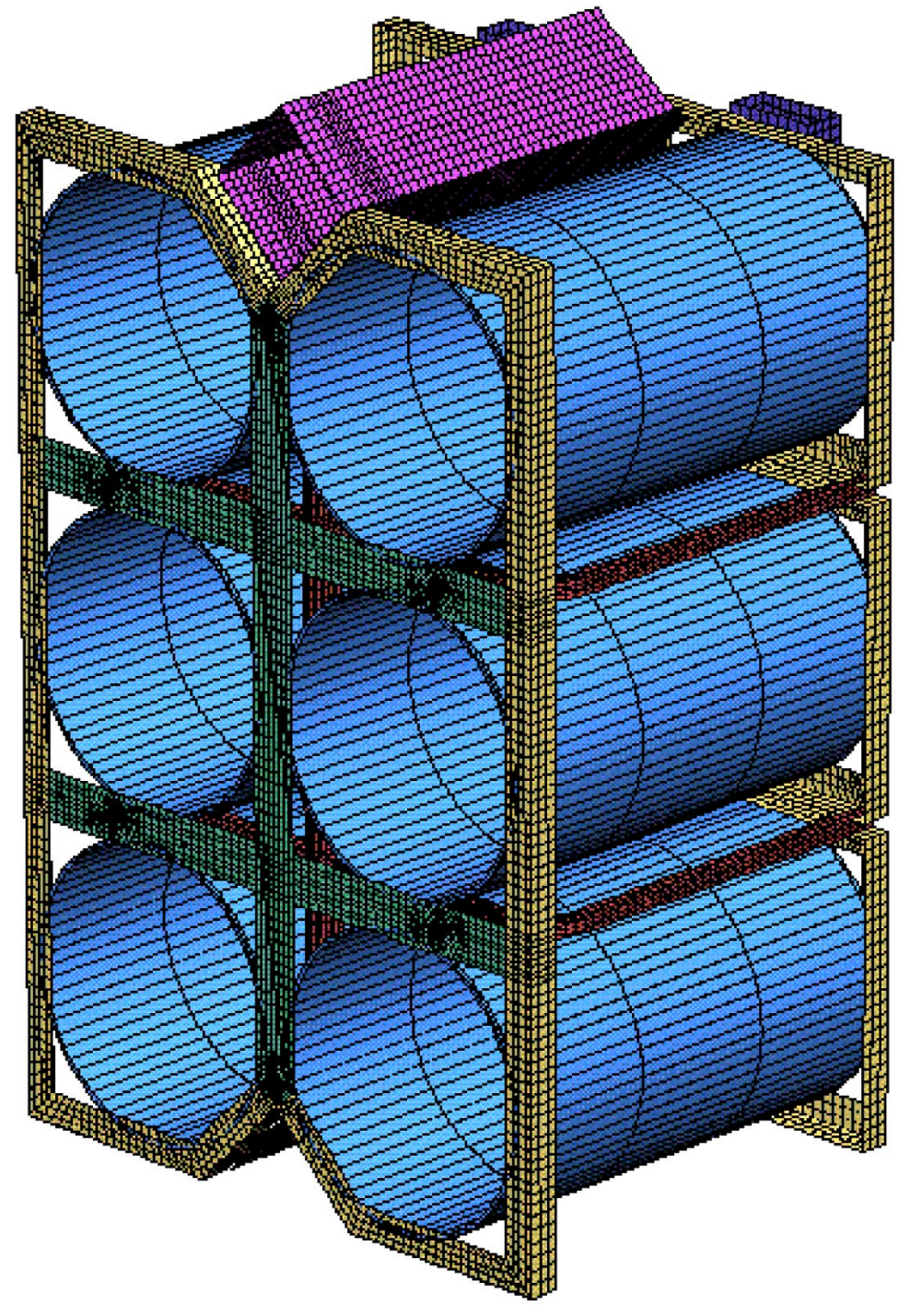

FIGURE 7: (above) The mesh used in analyzing the 6-pack assembly is relatively coarse in most places, finer near critical connections. All structural steel parts are modeled using shells.

\section{Methods}

The structural system was analyzed using a finite element method model. The program TrueGrid was used to generate the finite element mesh of the system (see Figure 7). The mesh contains 23658 first-order quadrilateral shell elements with elastic-plastic material models to model the structural steel parts. In addition, 12864 hexahedral brick elements with simple elastic material models were used to model the bolts. Finally, 2160 rigid shell elements were used to model the containers. Each container was modeled as a rigid body with only six degrees of freedom. Welds were simulated by merging coincident mesh nodes together, leaving a continuous mesh through each weld with no special boundary conditions. Finer meshes were used in regions known to exhibit larger stresses and stress gradients, particularly near highly stressed bolted and welded connections. In total, the model has 49109 nodes and 190449 active degrees of freedom. The weight calculated by TrueGrid for the 6-pack structure (without containers) is almost exactly $300 \mathrm{lbf}$, the figure reported by Mason \& Hanger. Slide surfaces (with friction) exist between (1) the containers and the base, (2) the containers and the cover, (3) the bolts and the base, and (4) the bolts and the cover. Figure 8 shows the mesh of hexahedral solid elements used to model each of the bolts.

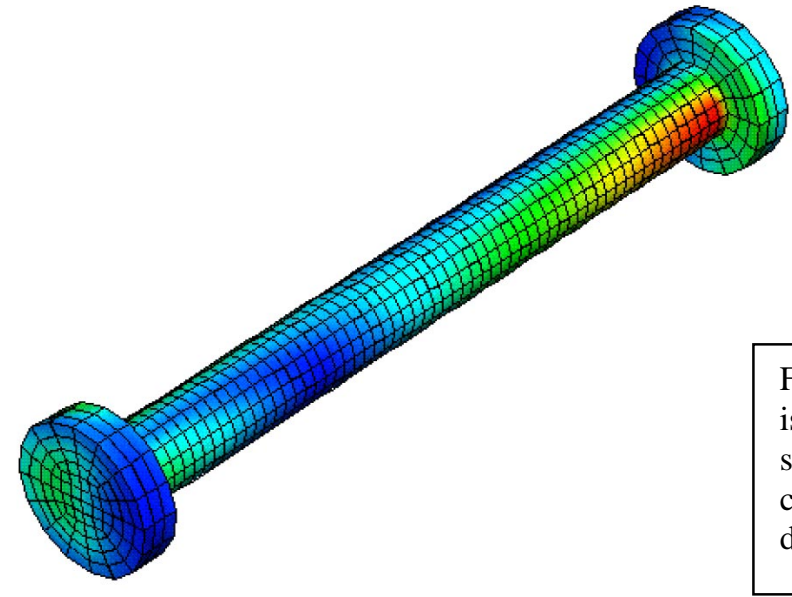

FIGURE 8: (left) The mesh used to model the bolts is composed of hexahedral (brick) elements. Slide surfaces apply forces to boltheads. The color contours show a typical effective stress distribution due to mostly axial load with some bending. 
NIKE3D, an LLNL-developed non-linear implicit three-dimensional finite element analysis code for solid and structural mechanics, was used to analyze the 6-pack pallet finite element model. GRIZ, also an LLNL code, was used to post-process the NIKE3D output data and generate element stresses. The elastic-plastic material model incorporates the decreased stress of plastically deforming sections in calculating moments and deflections in shell elements. Bolt preloads are applied by shrinking the bolt shaft materials axially. A computationally intensive iteration scheme makes the bolt preloads accurate to $3 \%$ of their desired quantities. The whole analysis process requires 3 to 4 days of computations on a DEC to complete preloading and all 4 load cases for a particular set of input parameters.

\section{Results}

Since this is a strength analysis, the generic "stress" reported here is the "effective" or "Von Mises" stress invariant, a scalar quantity that can be used to quantify safety margins. NIKE3D uses effective stress to determine whether the elastic limit has been reached or not. The stresses reported are either at an arbitrary location within a brick element (in bolts) or at a shell's mid-plane (in structural steel parts).

Various critical locations in the 6-pack base with possible local stress peaks are pointed out in Figure 9. Peak stresses in

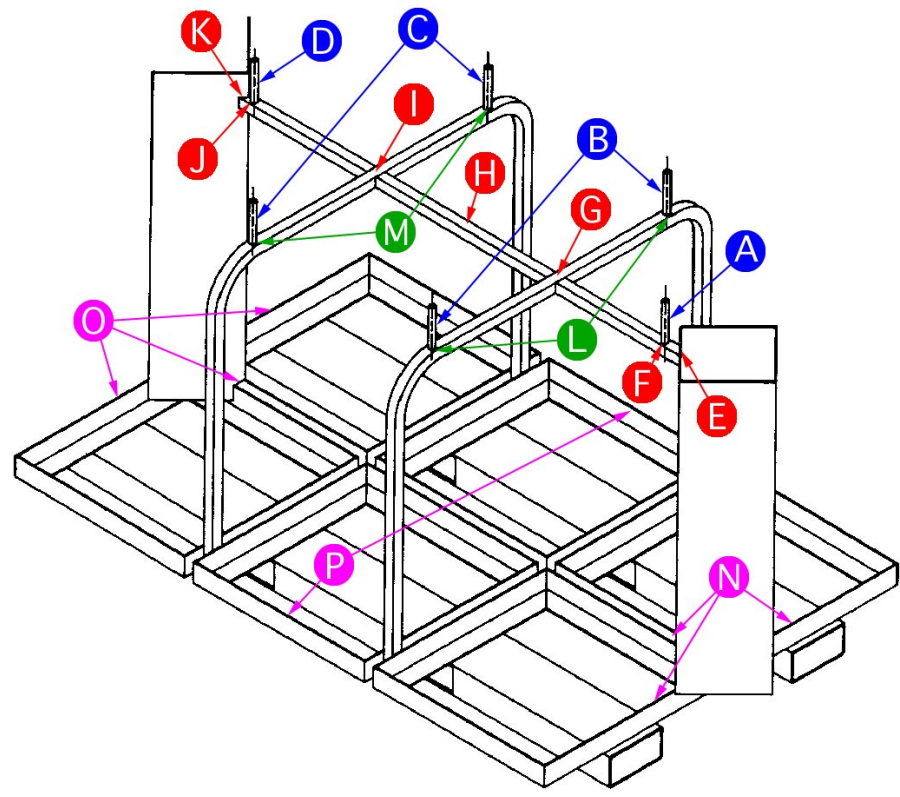
these locations for each of the 4 static load cases are tabulated in Table 1 for both a 6-pack pallet with 1/2" bolts and with 3/8" bolts. Load cases \#2 (upright) and \#4 (hanging) tend to be the most critical for all the locations. Also tabulated for each critical location is the factor of safety based on the yield stress and the highest stress encountered at that location for any of the load cases.

As shown in Table 1, multiple locations within the 6-pack would not satisfy a 3.0 factor of safety on yield criterion. High stress locations that may be of concern include tube cross-sections near the bolts (locations F, J, L \& M of Figure 9), the welds at either end of the main support (locations $\mathrm{E} \& \mathrm{~K}$ ) and the angles at the base of the full-diamond support (location $\mathrm{N}$ ). The simulations predict that the grade- 5 bolts have adequate safety factors. Analysis also predicts some yielding in the cover, especially near the bolt holes. There would be significantly more yielding if not all the containers were the same height. However, it is assumed here that the cover is not a critical load path member - that yielding in the cover is indeed permissible. Specific values of stresses and safety factors in the cover are therefore not reported. 


\begin{tabular}{|c|c|c|c|c|c|c|c|c|c|c|c|c|}
\hline \multicolumn{3}{|c|}{$\begin{array}{l}\text { SUMMARY OF 6-PACK ANALYSES } \\
\text { EFFECTIVE (Von Mises) STRESS VALUES (in psi) }\end{array}$} & \multicolumn{5}{|c|}{$1 / 2^{\prime \prime}$} & \multicolumn{5}{|c|}{$3 / 8$ BOLTS } \\
\hline \multicolumn{2}{|r|}{ LOCATION OF STRESS PEAK } & $\begin{array}{c}\text { YIELD } \\
\text { STRESS }\end{array}$ & $\begin{array}{c}\text { LOAD } \\
\text { CASE \#1 }\end{array}$ & $\begin{array}{c}\text { LOAD } \\
\text { CASE \#2 }\end{array}$ & $\begin{array}{c}\text { LOAD } \\
\text { CASE \#3 }\end{array}$ & $\begin{array}{c}\text { LOAD } \\
\text { CASE \#4 }\end{array}$ & $\begin{array}{l}\text { WORST } \\
\text { CASE } \\
\text { F.S. }\end{array}$ & $\begin{array}{c}\text { LOAD } \\
\text { CASE \#1 }\end{array}$ & $\begin{array}{c}\text { LOAD } \\
\text { CASE \#2 }\end{array}$ & $\begin{array}{c}\text { LOAD } \\
\text { CASE \#3 }\end{array}$ & $\begin{array}{c}\text { LOAD } \\
\text { CASE \#4 }\end{array}$ & $\begin{array}{l}\text { WORST } \\
\text { CASE } \\
\text { F.S. }\end{array}$ \\
\hline A & Bolt \#1 & 92000 & 5160 & 8360 & 7400 & 16100 & 5.71 & 9980 & 16400 & 15500 & 27800 & 3.31 \\
\hline B & Bolts \#2 \& 3 & 92000 & 6410 & 11400 & 11000 & 13100 & 7.02 & 12700 & 22400 & 21800 & 27800 & 3.31 \\
\hline C & Bolts \#4 \& 5 & 92000 & 6410 & 11000 & 10600 & 12900 & 7.13 & 12700 & 21900 & 21400 & 26300 & 3.50 \\
\hline D & Bolt \#6 & 92000 & 5130 & 9910 & 9410 & 15900 & 5.79 & 9920 & 17000 & 16300 & 21000 & 4.38 \\
\hline$E$ & Main Support Weld near Bolt \#1 & 46000 & 8470 & 15900 & 15300 & 12000 & 2.89 & 11700 & 20500 & 19900 & 16300 & 2.24 \\
\hline$F$ & Main Support at Bolt \#1 & 46000 & 6690 & 13000 & 12200 & 8200 & 3.54 & 8180 & 14700 & 14100 & 11100 & 3.13 \\
\hline G & Main/Lateral Support Junction near Bolt \#1 & 46000 & 2610 & 4930 & 4830 & 9810 & 4.69 & 3510 & 6240 & 6150 & 11800 & 3.90 \\
\hline $\mathbf{H}$ & Main Support at Mid-span & 46000 & 2590 & 4920 & 4770 & 5320 & 8.65 & 3560 & 6310 & 6190 & 6710 & 6.86 \\
\hline $\mathrm{I}$ & Main/Lateral Support Junction near Bolt \#6 & 46000 & 2640 & 5090 & 4930 & 8760 & 5.25 & 3560 & 6550 & 6400 & 10400 & 4.42 \\
\hline J & Main Support at Bolt \#6 & 46000 & 6360 & 11600 & 11400 & 19200 & 2.40 & 7790 & 13200 & 13000 & 20600 & 2.23 \\
\hline $\mathrm{K}$ & Main Support Weld near Bolt \#6 & 46000 & 8280 & 15000 & 14600 & 21500 & 2.14 & 11400 & 19300 & 19000 & 26000 & 1.77 \\
\hline $\mathbf{L}$ & Lateral Supports at Bolts \#2 \& 3 & 46000 & 13000 & 23900 & 23000 & 22500 & 1.92 & 14600 & 25200 & 24700 & 24200 & 1.83 \\
\hline M & Lateral Supports at Bolts \#4 \& 5 & 46000 & 13000 & 23700 & 23100 & 24100 & 1.91 & 14600 & 25100 & 24600 & 25900 & 1.78 \\
\hline $\mathrm{N}$ & Angles at Base of Full-Diamond & 36000 & 3020 & 4830 & 3890 & 12600 & 2.86 & 4080 & 5660 & 4860 & 13500 & 2.67 \\
\hline 0 & Angles at Base of Half-Diamond & 36000 & 3100 & 4850 & 3920 & 4730 & 7.42 & 4160 & 5670 & 4910 & 5310 & 6.35 \\
\hline $\mathbf{P}$ & Outer Base Angles at Middle Bay & 36000 & 3890 & 8340 & 8580 & 8730 & 4.12 & 5190 & 10800 & 11000 & 11100 & 3.24 \\
\hline
\end{tabular}

TABLE 1: Peak effective stress and overall safety factors at various 6-pack base locations of interest (shown in Figure 9). The results from 2 analyses are shown: for $1 / 2$ " bolts and for $3 / 8$ " bolts. The maximum stress over all 4 load cases encountered at each particular location is printed in blue. The factor of safety (defined as yield stress over maximum effective stress encountered) is printed in green if at least 3 and in red if less than 3.

The associated input and output files for the analyses discussed in this report are currently located on LLNL's Compass Cluster file system within the directory " $/$ dino/6pack/Final". Within this directory are two more directories named " $\mathrm{D}=0.375$ " and " $\mathrm{D}=0.5$ ", depending upon which bolt size is used. Each of these directories contains three complete analyses, entitled "LC1", "LC2-3" and "LC4" (load cases 2 and 3 are combined into one analysis). These directories contain "trugrdi", a TrueGrid input file; "trugrdo", the corresponding TrueGrid output file and NIKE3D input file; and assorted NIKE3D output files beginning with "n3". Usually "n3plot" and its continuation files are all that is necessary for running GRIZ and reviewing results.

\section{Discussion}

The worst factors of safety predicted are for the hanging load case (\#4) near bolts \#4 \& 5, shown in Figure 10. The problem here is that much of the $1 \times 1$ tube cross-section far from the neutral axis, the part most responsible for resisting the bending induced by the axial load in the bolt, is taken away by the bolt hole. This causes a stress concentration around the edges of the hole, particularly where the cross-section is a minimum (and right where the load is applied). If there was a flaw in the material near these bolt holes, it could cause significant yielding and too much deformation at these bolts. If the cover becomes too loose, a container could fall from its normal 


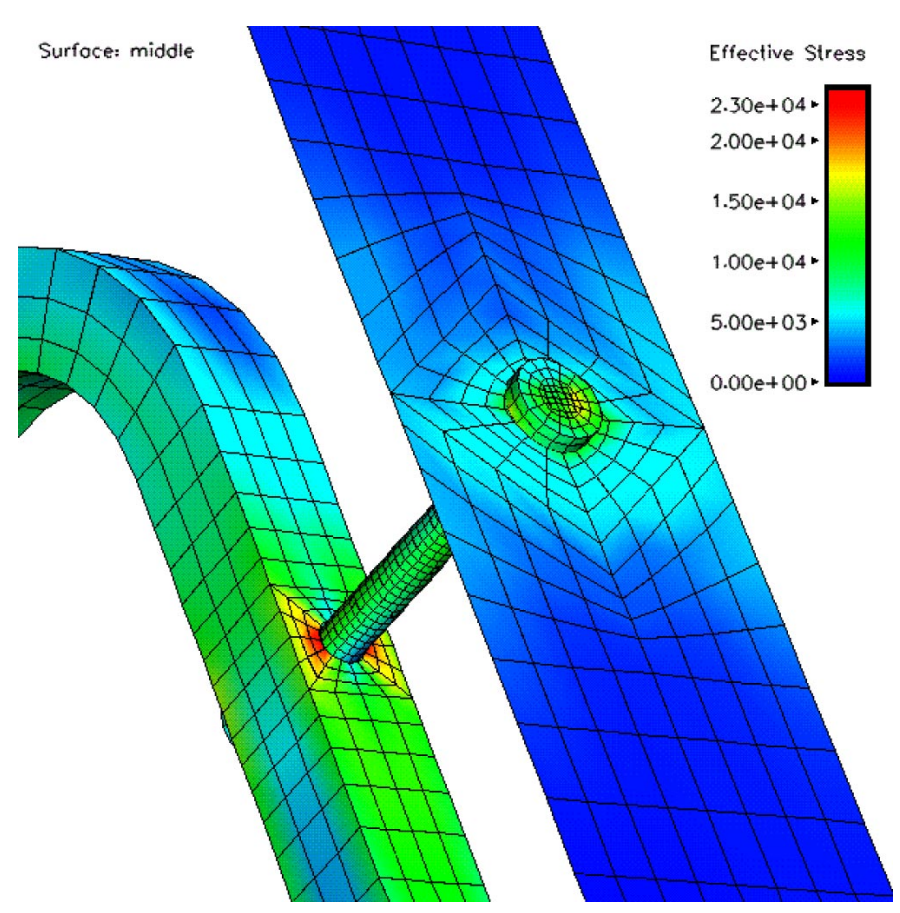

position in the 6-pack. Increasing the safety factor decreases the likelihood of such an event. Reinforcing these $1 \mathrm{x} 1$ tubular sections at the lateral bolts may overcome this problem.

FIGURE 10: Effective stress at location M (lateral supports near bolts \#4 \& 5) during load case \#4 (hanging) for the 6-pack with $3 / 8$ " bolts. A stress concentration occurs because of the hole where the bending moment is highest. Blue and green areas have a factor of safety of 3 or better. Yellow and orange regions have a factor of safety between 3 and 2 . Bright red areas have a factor of safety less than 2 . Similar effective stress magnitudes exist on the opposite side of the $1 \times 1$ tube section.

Another area of concern is at the junctions between the main support beam and the full-diamond and half-diamond supports on either end of the 6-pack, shown in Figure 11. The stress peak here is located right on the 6-pack's plane of symmetry, at the tip of the curved plate that makes up the support, a reasonable location for a stress concentration. Similar to the above case, there are also large stresses around the nearby bolts (\#1 \& 6). Large upward concentrated forces along the beam contribute to a large bending moment near these very stiff supports, and therefore very large bending stresses. The situation is slightly worse at the half-diamond end near bolt \#6. If a crack was present due to a welding error, or if the joint was structurally weak for some other

FIGURE 11: Effective stress at locations $\mathbf{J}$ \& K (main support at bolt \#6 and weld) during load case \#4 (hanging) for the 6-pack with $3 / 8$ " bolts (viewed from below with boltheads removed for increased visibility). A stress concentration occurs at the welded junction with the half-diamond support's corner. Blue and green areas have a factor of safety of 3 or better. Yellow and orange regions have a factor of safety between 3 and 2. Bright red areas have a factor of safety less than 2. Slightly lesser effective stress magnitudes exist on the opposite side of the $2 \times 1$ tube section. The peak stress does occur right at the welded seam between parts, though the post-processor reports nodal stresses that are averages of stresses from adjoining elements.

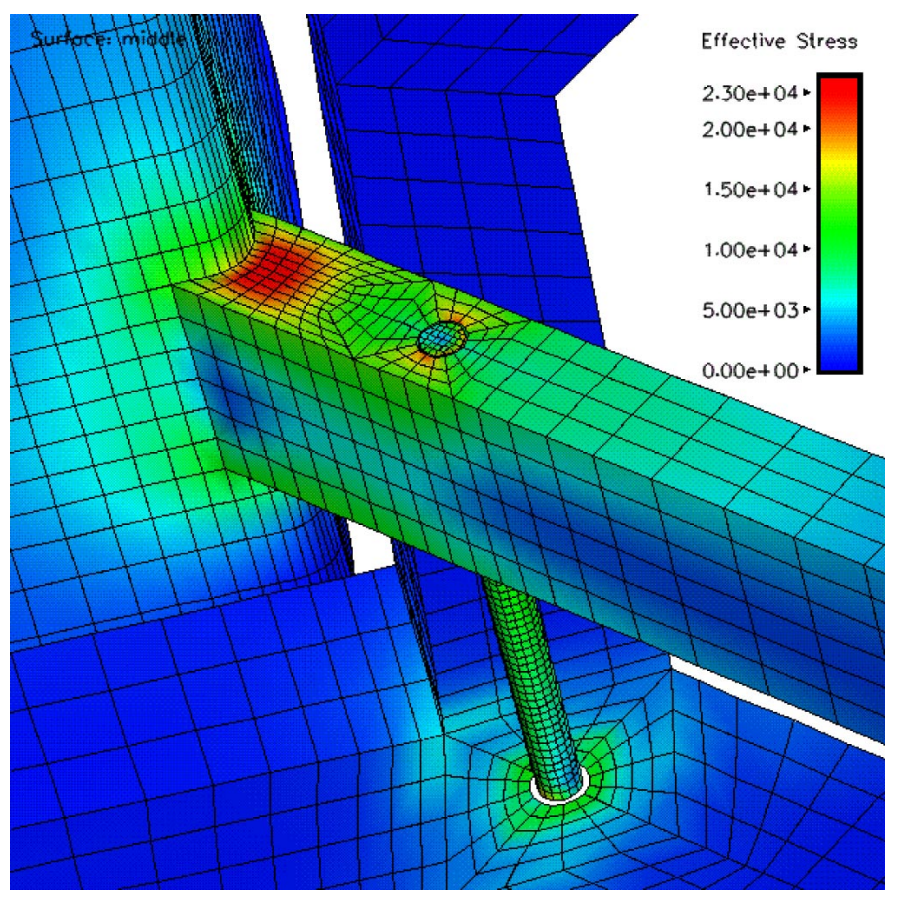


reason, this could cause the joint to yield significantly. Too much deformation could result in a failure that would drop all the barrels. Adding more material along the sides of the main support where it joins the diamond supports could also reinforce this region.

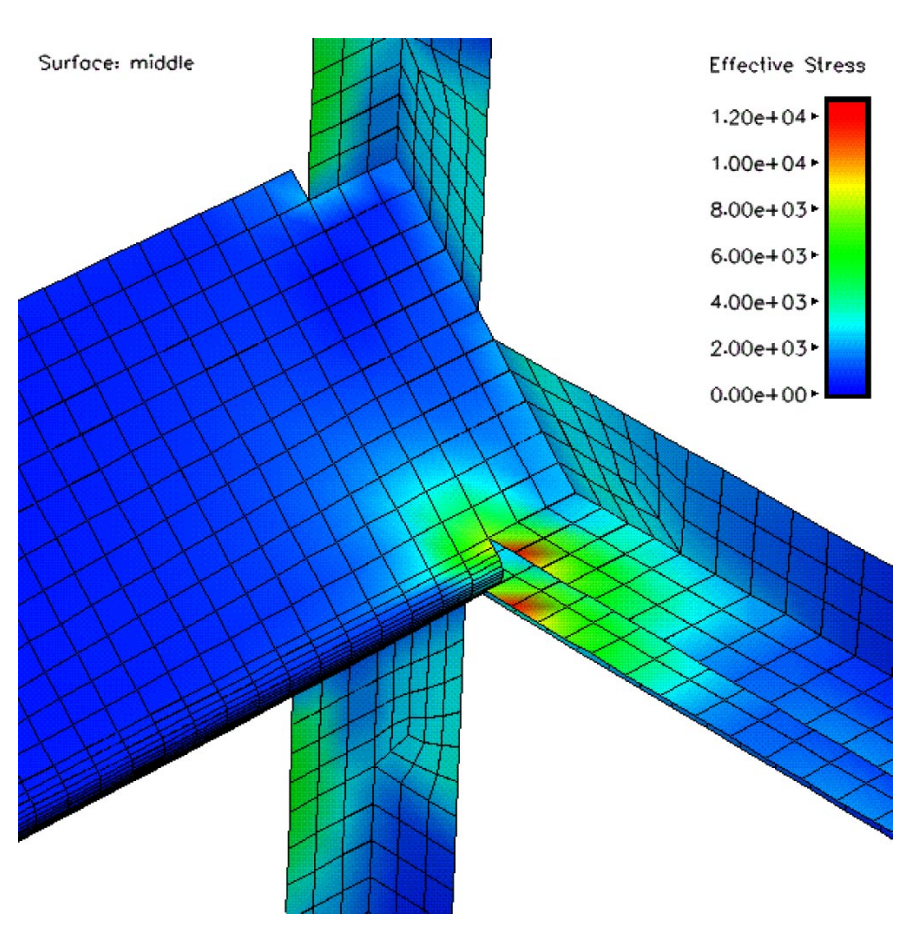

FIGURE 12: Effective stress at location N (angles at base of full-diamond support) during load case \#4 (hanging) for the 6-pack with $3 / 8$ " bolts. A stress concentration occurs because of the large moment transmitted around this corner. Only the bright red areas have a factor of safety less than 3 .
A final location of high stress exists at the bottom of the large diamond support where it is welded to the base angle bays supporting it, shown in Figure 12. When hanging (load case \#4), the weight of most of the base and any reactions through the base angles are transmitted through this $90^{\circ}$ connection. This condition, though probably not as conducive to a quick fix, is not as severe as some of the previously mentioned ones are.

It is interesting to note that load case \#3 (stacked) tends to be less severe than load case \#2 (upright). This does make intuitive sense. Assembly tends to make the central portion of the $2 \times 1$ main support bow outward. The increased weight from above tends to rectify this bowing, providing more confinement. This stacked state exhibits less deformation in general and therefore smaller stresses at its weaker points.

To gain more insight into the load path through the 6-pack pallet, stresses were integrated across bolt cross-sections to determine the amounts of axial and shear load passing through them. These findings are summarized in Table 2. Note that as long as the 6-pack is sitting on the floor some way (load cases \#1, 2 \& 3) there is relatively little shear in the bolts. For the hanging case (load case \#4), more load is transmitted up through the bottom of the base than through the bolts. This happens mostly because the forklift tubes make the bottom of the base much stiffer than the bolted top (therefore making the bottom pick up more load), but also because moments exist around each container to prevent it from tipping out of its bin. 


\begin{tabular}{|c|c|c|c|c|c|c|c|c|c|}
\hline \multicolumn{2}{|c|}{$\begin{array}{l}\text { SUMMARY OF 6-PACK ANALYSES } \\
\text { BOLT FORCE VALUES (in lbf) }\end{array}$} & \multicolumn{4}{|c|}{$1 / 2 "$ BOLTS } & \multicolumn{4}{|c|}{$3 / 8 "$ BOLTS } \\
\hline & LOCATION & $\begin{array}{l}\text { LOAD } \\
\text { CASE } \\
\# 1 \\
\end{array}$ & $\begin{array}{l}\text { LOAD } \\
\text { CASE } \\
\# 2\end{array}$ & $\begin{array}{l}\text { LOAD } \\
\text { CASE } \\
\# 3 \\
\end{array}$ & $\begin{array}{l}\text { LOAD } \\
\text { CASE } \\
\# 4 \\
\end{array}$ & $\begin{array}{l}\text { LOAD } \\
\text { CASE } \\
\# 1 \\
\end{array}$ & $\begin{array}{l}\text { LOAD } \\
\text { CASE } \\
\# 2 \\
\end{array}$ & $\begin{array}{l}\text { LOAD } \\
\text { CASE } \\
\# 3\end{array}$ & $\begin{array}{l}\text { LOAD } \\
\text { CASE } \\
\# 4\end{array}$ \\
\hline \multirow{7}{*}{ 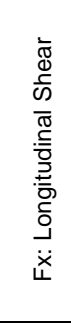 } & Bolt \#1 & -13 & -11 & -7 & -73 & -8 & -7 & -5 & -54 \\
\hline & Bolt \#2 & -3 & 4 & 4 & -32 & -3 & 3 & 3 & -35 \\
\hline & Bolt \#3 & -3 & 4 & 4 & -32 & -3 & 3 & 3 & -35 \\
\hline & Bolt \#4 & 2 & 9 & 9 & -28 & 3 & 11 & 12 & -27 \\
\hline & Bolt \#5 & 2 & 9 & 9 & -28 & 3 & 11 & 12 & -27 \\
\hline & Bolt \#6 & 13 & 31 & 29 & -62 & 8 & 17 & 15 & -30 \\
\hline & All Bolts & -1 & 45 & 49 & -254 & -1 & 38 & 40 & -209 \\
\hline \multirow{7}{*}{ 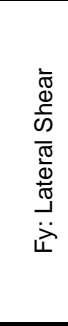 } & Bolt \#1 & 0 & 0 & 0 & 0 & 0 & 0 & 0 & 0 \\
\hline & Bolt \#2 & 27 & 39 & 37 & 37 & 22 & 32 & 31 & 33 \\
\hline & Bolt \#3 & -27 & -39 & -37 & -37 & -22 & -32 & -31 & -33 \\
\hline & Bolt \#4 & 27 & 39 & 37 & 34 & 22 & 32 & 31 & 33 \\
\hline & Bolt \#5 & -27 & -39 & -37 & -34 & -22 & -32 & -31 & -33 \\
\hline & Bolt \#6 & 0 & 0 & 0 & 0 & 0 & 0 & 0 & 0 \\
\hline & All Bolts & 0 & 0 & 0 & 0 & 0 & 0 & 0 & 0 \\
\hline \multirow{7}{*}{ 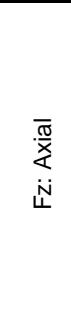 } & Bolt \#1 & 429 & 741 & 742 & 568 & 571 & 934 & 926 & 862 \\
\hline & Bolt \#2 & 429 & 765 & 736 & 736 & 572 & 960 & 921 & 984 \\
\hline & Bolt \#3 & 429 & 765 & 737 & 737 & 571 & 958 & 920 & 982 \\
\hline & Bolt \#4 & 429 & 763 & 737 & 731 & 571 & 957 & 921 & 998 \\
\hline & Bolt \#5 & 429 & 763 & 737 & 732 & 570 & 956 & 919 & 997 \\
\hline & Bolt \#6 & 429 & 779 & 738 & 887 & 571 & 972 & 919 & 1096 \\
\hline & All Bolts & 2572 & 4577 & 4427 & 4391 & 3428 & 5736 & 5525 & 5919 \\
\hline
\end{tabular}

TABLE 2: Axial and shear force magnitudes in bolts for both bolt size assemblies and all load cases.

\section{Conclusion}

Static finite-element structural analyses were performed to assess the strength of the 6-Pack Container Pallet used by Mason \& Hanger Co., Inc. The analysis predicts that the 6-pack pallet, when used with AL-R8-SI containers and manipulated as usual, would not meet a safety factor of at least 3.0 on yield at all locations in the main load-bearing sections of the assembly. Also, small amounts of localized yielding were found in the cover near the bolted connections. The decision whether or not to proceed with use of the current design and procedure depends upon what guidelines are established as acceptable design criteria for fixtures used with AL-R8-SI containers and their contents. 